\title{
Fine scale mapping of malaria infection clusters by using routinely collected health facility data in urban Dar es Salaam, Tanzania
}

\author{
Yeromin P. Mlacha, ${ }^{1,2}$ Prosper P. Chaki, ${ }^{1}$ Alpha D. Malishee, $, 1,3$ \\ Victoria M. Mwakalinga, ${ }^{1,4}$ Nicodem J. Govella, ${ }^{1}$ Alex J. Limwagu, ${ }^{1}$ John M. Paliga, ${ }^{1}$ Daniel F. \\ Msellemu, ${ }^{1}$ Zawadi D. Mageni, ${ }^{1}$ Dianne J. Terlouw, ${ }^{5,6}$ Gerry F. Killeen, ${ }^{1,2}$ Stefan Dongus ${ }^{1,2,7,8}$ \\ ${ }^{1}$ Environmental Health and Ecological Sciences Thematic Group, Ifakara Health Institute, Dar es Salaam, \\ Tanzania; ${ }^{2}$ Vector Biology Department, Liverpool School of Tropical Medicine, Liverpool, UK; ${ }^{3}$ College of \\ Information and Communication Technologies, University of Dar es Salaam, Dar es Salaam, Tanzania; \\ ${ }^{4}$ School of Public Health, Faculty of Health Sciences, University of the Witwatersrand, Johannesburg, \\ South Africa; ${ }^{5}$ Department of Clinical Sciences, Liverpool School \\ of Tropical Medicine, Liverpool, UK; ${ }^{6}$ Malawi-Liverpool-Wellcome Trust Clinical Research Programme, \\ College of Medicine, Blantyre, Malawi; ${ }^{7}$ Department of Epidemiology and Public Health, Swiss Tropical \\ and Public Health Institute, Basel; ${ }^{8}$ University of Basel, Basel, Switzerland
}

\author{
Correspondence: Stefan Dongus, Department of Epidemiology and \\ Public Health, Swiss Tropical and Public Health Institute, Socinstrasse \\ 57, 4002 Basel, Switzerland. \\ Tel: +41.61.2848111 - Fax: +41.61 .2848105 . \\ E-mail: stefan.dongus@unibas.ch
}

Key words: Malaria; Spatial heterogeneity; Hot spots; GIS; Tanzania.

Ethical statement: ethical approval was obtained from the Institutional Review Board of the Ifakara Health Institute (Approval A.50), the National Institute of Medical Research in Tanzania (Approval NIMR/HQ.R.8a/Vol IX/801) and the Masters Review Panel and Research Ethics Committee of the Liverpool School of Tropical Medicine (Approval 09.60).

Acknowledgements: we thank the staff of the Buguruni Health Centre, the Ilala Municipal Medical Office of Health and the Dar es Salaam City Medical Office of Health, as well as the neighbourhood chairmen and executive officers for their cooperation and assistance. We are grateful to M. Hamel, J. Stevenson, J. Cox and C.J. Drakeley for stimulating discussions that informed the design and interpretation of this study.

Funding: funding was kindly provided by the Wellcome Trust (www.wellcome.ac.uk) through a Masters fellowship awarded to YPM (096358/Z/11/Z), the Bill \& Melinda Gates Foundation (www.gatesfoundation.org) through the Malaria Transmission Consortium (Award 41151), and the Swiss National Centre of Competence in Research North-South (www.north-south.unibe.ch) through a $\mathrm{PhD}$ stipend awarded to SD. VMM was supported through a PhD fellowship from the Consortium for Advanced Research Training in Africa (www.cartafrica.org), jointly led by the African Population and Health Research Center (aphrc.org) and the University of the Witwatersrand (www.wits.ac.za). VMM was also supported by a Hassan Mshinda Career Development Fellowship, which was collaboratively funded by the Liverpool School of Tropical Medicine (www.lstmed.ac.uk) and the Ifakara Health Institute (www.ihi.or.tz). The funders had no role in study design, data collection and analysis, decision to publish, or preparation of the manuscript.

\begin{abstract}
This study investigated whether passively collected routine health facility data can be used for mapping spatial heterogeneities in malaria transmission at the level of local government housing cluster administrative units in Dar es Salaam, Tanzania. From June 2012 to January 2013, residential locations of patients tested for malaria at a public health facility were traced based on their local leaders' names and geo-referencing the point locations of these leaders' houses. Geographic information systems (GIS) were used to visualise the spatial distribution of malaria infection rates. Spatial scan statistics was deployed to detect spatial clustering of high infection rates. Among 2407 patients tested for malaria, $46.6 \%$ (1121) could be traced to their 411 different residential housing clusters. One small spatially aggregated cluster of neighbourhoods with high prevalence was identified. While the home residence housing cluster leader was unambiguously identified for
\end{abstract}

Contributions: YPM, SD, GFK, and DJT designed the study with support from PPC and NJG; YPM implemented the study; YPM and SD analysed the data and drafted the manuscript with support from GFK and DJT; VMM, ADM, AJL, JMP, DFM, and ZDM supported the study implementation and data analysis; SD prepared the maps.

Received for publication: 6 July 2016.

Revision received: 18 January 2017.

Accepted for publication: 27 January 2017.

CCopyright Y.P. Mlacha et al., 2017

Licensee PAGEPress, Italy

Geospatial Health 2017; 12:494

doi:10.4081/gh.2017.494

This article is distributed under the terms of the Creative Commons Attribution Noncommercial License (CC BY-NC 4.0) which permits any noncommercial use, distribution, and reproduction in any medium, provided the original author(s) and source are credited. 
$73.8 \%(240 / 325)$ of malaria-positive patients, only $42.3 \%$ $(881 / 2082)$ of those with negative test results were successfully traced. It was concluded that recording simple points of reference during routine health facility visits can be used for mapping malaria infection burden on very fine geographic scales, potentially offering a feasible approach to rational geographic targeting of malaria control interventions. However, in order to tap the full potential of this approach, it would be necessary to optimise patient tracing success and eliminate biases by blinding personnel to test results.

\section{Introduction}

In many endemic countries of sub-Saharan Africa (D'Acremont et al., 2010; Gething et al., 2010b; Maharaj et al., 2012; Murray et al., 2012; O'Meara et al., 2010; WHO, 2013), including the United Republic of Tanzania (Bhattarai et al., 2007; Mtove et al., 2011; WHO, 2013), malaria incidence and morbidity rates have substantially decreased in recent years, following the successful scale-up of available front-line malaria intervention tools (Bhattarai et al., 2007; Ceesay et al., 2008; Steketee and Campbell, 2010). These reductions of malaria transmission have encouraged a paradigm shift from the goal of burden control to pathogen elimination (Feachem et al., 2010; Kitua et al., 2011; Moonen et al., 2010a; Steketee and Campbell, 2010).

Human malaria infection distributions are known to exhibit spatial heterogeneities on very fine scales. They may even vary between households within the same communities, particularly at low-transmission intensities (Bousema et al., 2010b, 2012; Gaudart et al., 2006; Mirghani et al., 2010; Woolhouse et al., 1997). In areas where malaria transmission is low enough to enable implementation of the pre-elimination phase (WHO, 2007, 2012), information on the spatial distribution of remaining malaria infections is required to enable targeting of supplementary disease control interventions (Bejon et al., 2010; Bousema et al., 2010b, 2012; Nourein et al., 2011; malERA Consultative Group on Monitoring, 2011; WHO, 2012). Spatially aggregated clusters of high infection rates, often referred to as pockets of transmission (Tambo et al., 2014; Zhou et al., 2013) or hotspots, have been identified through a variety of survey methods (Bejon et al. 2010, 2014; Bousema et al. 2010a, 2010b; Clark et al., 2008; Hardy et al., 2015). A hotspot of malaria transmission may be defined as an area with a significantly higher proportion of positive malaria test results compared to its surrounding area (Bousema et al., 2010a).

Most of the standard measures for monitoring and mapping malaria transmission that have been used by research projects and by national monitoring and evaluation programmes have relied on surveys of well-defined demographic and spatial samples of relevant human populations (Bejon et al., 2010; Bousema et al., 2010a, 2010b; Clark et al., 2008; Teuscher, 1992). The greatest strength of population-weighted cross-sectional prevalence surveys is the representative nature of such probability sampling (Chanda et al., 2012; Moonen et al., 2010b; Roll Back Malaria, 2006; Rowe et al., 2009). However, national malaria indicator surveys and other household survey approaches are not designed or powered to determine local-level variation and are typically too costly and laborious to apply with sufficient sampling intensity to obtain spatial resolution finer than the district-level outside of research settings with limited geographic scope (Bousema et al., 2010b; WHO, 2012). The challenge remains to develop program- matically affordable and scalable approaches that deliver high-resolution maps of transmission risk for targeting supplementary control efforts, thus contributing to establishing effective surveillanceresponse systems (Tambo et al., 2014; Zhou et al., 2013), specifically in areas of low transmission where elimination may be feasible (Bejon et al., 2010, 2014; Bousema et al., 2010a, 2012; Mueller et al., 2011).

Passively collected routine health facility data are widely used to estimate the burden of malaria (Chanda et al., 2012; Gething et al., 2010a; Lippeveld et al., 2000; WHO, 2012) and for risk mapping in resource-limited settings. A common feature of those riskmapping approaches, however, is the considerable effort put into mapping the geographical coordinates of every participating household individually (Bejon et al., 2014; Bisanzio et al., 2015; Cohen et al., 2010, 2013; Ernst et al., 2006; Kazembe et al., 2006; Sturrock et al., 2014; Yeshiwondim et al., 2009). Several studies have shown that passive case detection at health facilities could guide reactive case detection, whereby visits are made to the respective residence of each positive case reported at a health facility to screen household members and neighbours (Branch et al., 2005; Brooker et al., 2004; Cohen et al., 2013; Kreuels et al., 2008; Maharaj et al., 2012; Pinchoff et al., 2015; Zanzibar Malaria Control Programme, 2010). Furthermore, data collection at health facilities during routine patient visits can allow the mapping of the spatial distribution of malaria infection burden (Alemu et al., 2013; de Oliveira et al., 2011; Kazembe, 2007; Wimberly et al., 2012; Zacarias and Andersson, 2011) as well as a variety of other diseases (Jennings et al., 2005; Lengeler et al., 1991; Mayala et al., 2004; Tornheim et al., 2010), across patient catchment areas (Oduro et al., 2011).

In Dar es Salaam, health facility data have been used for assessing the sensitivity and specificity of malaria diagnostic tools, as well as the quality of case management and health worker performance (Eriksen et al., 2007; Kahama-Maro et al., 2011; Nsimba et al., 2002). However, routinely collected health facility data have not yet been fully explored for mapping malaria infection burdens across the city, or for planning targeted delivery of appropriate control strategies, because patient records generally do not include accurate residential addresses. This exploratory study assesses the feasibility, cost, strengths and limitations of using anonymised routine health facility data, supplemented with the names of patients' local government housing cluster leaders as geographic reference points, to map their home residence locations, and the usefulness of this approach for visualising the spatial distribution of malaria prevalence in two adjacent wards of urban Dar es Salaam.

\section{Materials and Methods}

\section{Study area}

Dar es Salaam is located on the Indian Ocean coast of Tanzania in East Africa (Figure 1) with a population of 4.4 million inhabitants in 2012 (United Republic of Tanzania, 2013). The city is characterised by highly heterogeneous land use, including industrial and commercial areas, planned residential areas and informal settlements, as well as areas with urban agriculture (Dongus et al., 2009). Dar es Salaam has a hot and humid tropical climate throughout the year, with two rainy seasons: the long rains, which usually fall between March and May, and the short rains, which 
occur less predictably anytime between October and January. Average annual rainfall is $1042 \mathrm{~mm}$ (DCP, 2004) and the average temperature $25.9^{\circ} \mathrm{C}$. Malaria transmission in Dar es Salaam is perennial but relatively low following scale-up of insecticidal net coverage, house screening and larviciding, with a mean prevalence of detectable infection among residents in all age groups of approximately $10 \%$ (Msellemu et al., 2016) and an entomological inoculation rate of less than one infectious bite per person per year that both usually peak during and immediately after the main rainy season (Geissbühler et al., 2007; Maheu-Giroux and Castro, 2013; Namango, 2012).

\section{Study design}

Dar es Salaam is divided into five administrative levels [city, municipality, ward, neighbourhood and ten-cell-unit (TCUs)] in order of declining geographic scale (de Castro et al., 2004; Dongus et al., 2007). The TCU normally comprises between 10 and 100 houses or compounds with an elected leader who represents the residents (Dongus et al., 2007). While the municipal and city councils of Dar es Salaam do implement a numbering system for houses in the region, this is only applied to formally planned settlements and very few people know the identification number of the house that they live in. In the absence of a widely used system of neighbourhood names and house numbers or postal codes, similar to those which are used in other parts of the world as a spatial reference system for residential locations, TCUs are attractive as a geo- graphic frame of reference and have already proven useful as subdivisions for implementing and managing malaria surveillance and control in this city (Chaki et al., 2011, 2012; Dongus et al., 2007, 2011). However, patient registries of health facilities in Tanzania currently only record residential home location down to the neighbourhood level comprising an average of 70 TCUs each. Therefore, in order to be able to assign patient information to a residential location at much finer spatial resolution, the name of the patient's home TCU leader was added to the information recorded in the health facility registry in the context of this study.

In Tanzania, there are five levels of service in the public health care system, but only three are managed under the Dar es Salaam City Medical Office of Health (Mtasiwa et al., 2003): districts/municipalities (each with a municipal hospital), divisions (each with a health centre) and wards (with dispensaries and affiliated clinics). There is one public health facility per ward (called dispensary), which provides service at a lower cost than private facilities (Mamdani and Bangser, 2004). This study was conducted at Buguruni Health Centre (BHC), a division-level facility located close to the boundary between the Buguruni and Vingunguti wards (Figure 2). BHC was selected because its malaria rapid diagnostic test (mRDT) procedures had been quality-controlled by previous research projects indicating adequate quality of the services provided according to the national guidelines for management of fever and malaria cases (United Republic of Tanzania, 2006). Initial examination of the laboratory registry book revealed that the BHC

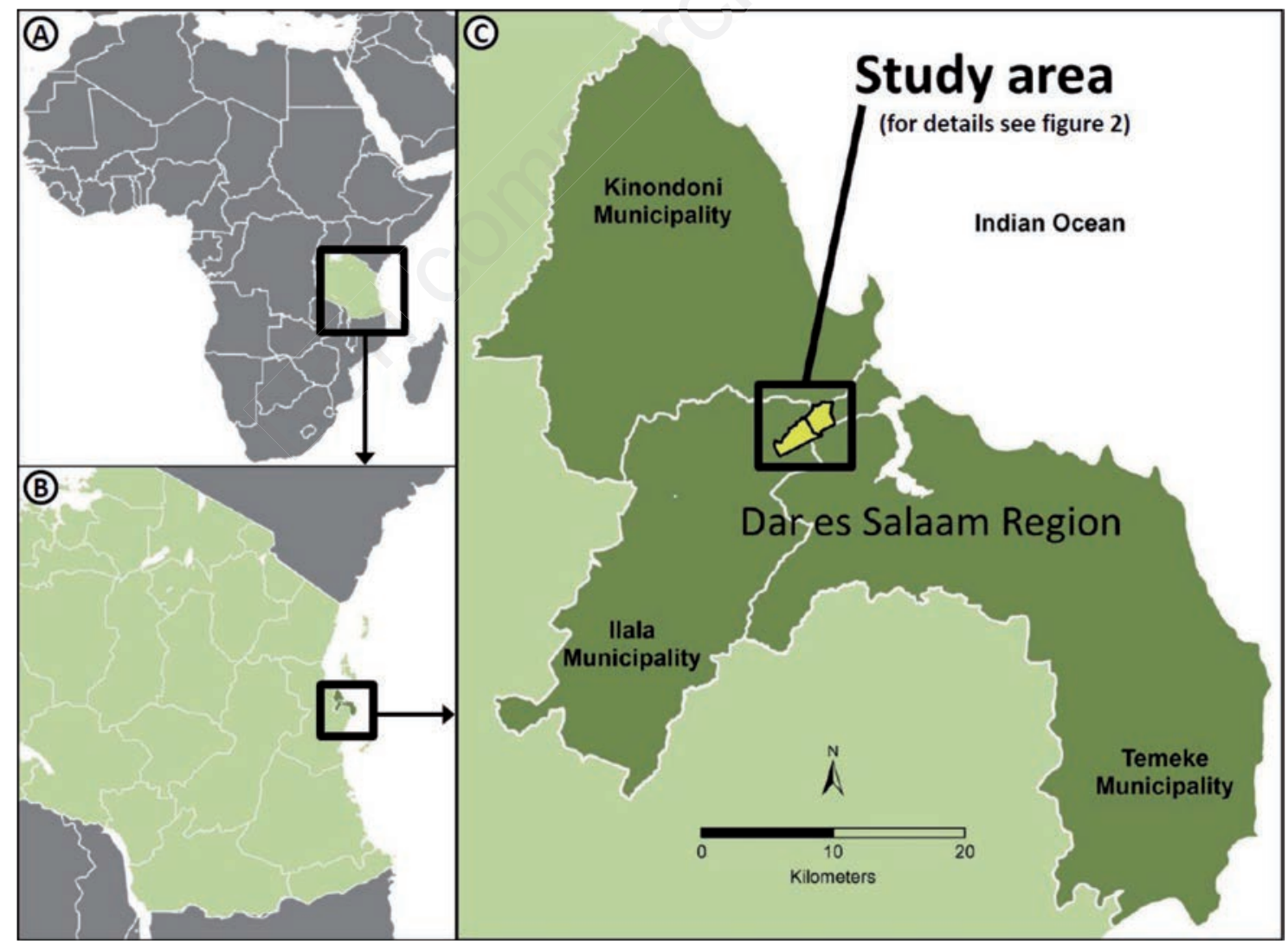

Figure 1. Location of study area in Dar es Salaam, Tanzania. Overview map of Africa (A); overview map of Tanzania (B); overview map of Dar es Salaam Region, indicating the location of the study area (C) (Buguruni and Vingunguti wards, see Figure 2). 
served patients across all of Dar es Salaam. The majority of patients, however, came from Buguruni $(29.8 \%)$ or Vingunguti wards $(25.2 \%)$. For demonstration purposes, this pilot study exclusively considered patients coming from these two wards. All individuals tested for malaria with an mRDT and treated according to the national guidelines for management of fever and malaria cases were eligible for inclusion in this study. The two study wards have a combined total area of $7.9 \mathrm{~km}^{2}$ and are subdivided into a total of eight neighbourhoods (Kisiwani, Mnyamani, Malapa, Madenge,
Kombo, Mtambani, Mtakuja and Miembeni) (Figure 2), with a total of 177,531 inhabitants based on 2012 national census data (The United Republic of Tanzania, 2013). Both wards are characterised by high housing density, largely unplanned settlements, low socio-economic background and relatively small TCU sizes (on average approximately $100 \times 100 \mathrm{~m}$ ) (Dongus et al., 2007). They are bordered by industrial areas to the south, and one of the largest river valleys cutting through Dar es Salaam (Msimbazi River) to the north.

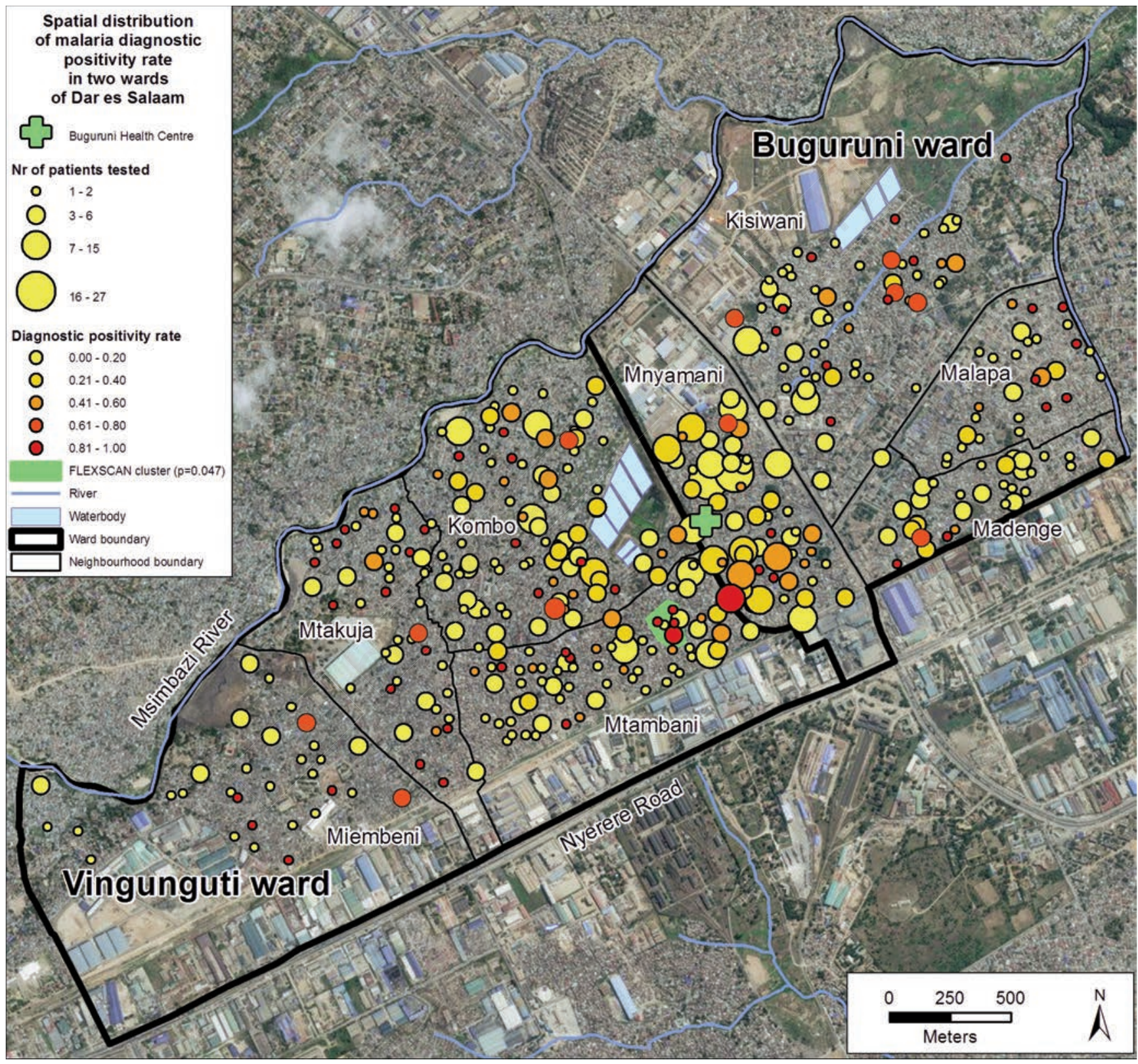

Figure 2. Spatial distribution of malaria diagnostic positivity rate (i.e. the proportion of patients tested for malaria that had a positive test result) in two wards of Dar es Salaam (Buguruni and Vingunguti). The size of the dots is proportional to the number of tested patients. The locations of the dots refer to residential housing cluster (TCU) locations, represented by the location of the TCU leader's house. The spatial cluster $(\mathrm{P}=\mathbf{0 . 0 4 7})$ of high malaria diagnostic positivity rate (based on FleXScan analysis) is marked in green. All results based on data from patients tested for malaria at Buguruni Health Centre (BHC) from June 2012 to January 2013. This figure was created using ArcGIS ${ }^{\circledR}$ software by Esri (www.esri.com). ArcGIS ${ }^{\circledR}$ and ArcMap ${ }^{\mathrm{TM}}$ are the intellectual property of Esri and are used herein under license. Copyright ${ }^{\odot}$ Esri. All rights reserved. Source of basemap (World Imagery): Esri, DigitalGlobe, GeoEye, Earthstar Geographics, CNES/Airbus DS, USDA, USGS, AeroGRID, IGN, and the GIS User Community. 


\section{Data collection}

Personal and clinical data, mRDT (MAL-Pf ${ }^{\circledR}$, ICT Diagnostics, Cape Town, South Africa) using histidine-rich protein II (HRP-II) results of individual patients attending the BHC, as well as the names of their local TCU leaders at their home residence were recorded routinely in the BHC laboratory registry books from June 2012 to January 2013.

Residential TCU locations were traced by comparing TCU leaders' names provided by patients to a list provided by the local government ward executive office where the details are recorded, regulated and regularly updated. Ward-level local government staff was consulted to solve unclear cases. Due to numerous, recent changes of TCU leaders resulting from routine electoral political processes, the previously described TCU maps and supporting databases (Dongus et al., 2007, 2011) had to be updated. Validating the exact TCU boundaries and re-mapping them where changes had occurred would have been too labour-intensive. The much more affordable and practical approach taken, which nevertheless allowed for the same level of spatial precision as TCU boundary maps, was to geolocate the residences of all TCU leaders in Buguruni and Vingunguti that were successfully identified from patient records at BHC, using a hand-held Global Positioning System (GPS) receiver (eTrex 10; Garmin, Olathe, KS, USA), at a positional precision of $\leq 5 \mathrm{~m}$.

\section{Data analysis}

Patient data were anonymised during the process of data extraction from the registry books to specific data collection sheets. Data sheets were checked for consistency and accuracy and entered into a Microsoft Excel database. Data were crosschecked against BHC registry records, aggregated by TCU, and linked to GPS coordinates of the respective TCU leaders' residential locations with unique enumeration codes for each TCU. The resulting geo-database was then integrated into Geographic Information Systems (GIS) ArcGIS 10.1 software (ESRI, Redland, CA, USA). This enabled the visualisation of the spatial distribution of positive and negative test results of patients, and the diagnostic positivity rate, i.e. the number of patients in each TCU who tested positive for Plasmodium falciparum malaria divided by the total number of patients tested in this TCU. Global Moran's I statistics in ArcGIS were used to test for spatial autocorrelation in the diagnostic positivity rates found in the different residential locations (Moran, 1948). Spatial clustering was assessed on ward, neighbour- hood and TCU levels. For wards and neighbourhoods, generalised linear modelling analyses (binomial distribution) were performed with R software (Rx642.15.2) with prevalence (i.e. the proportion of patients tested for malaria that had a positive test result) as the dependent variable and neighbourhoods and wards as categorical independent variables. At the TCU level, spatial clustering of high prevalence rates was assessed by performing spatial scan statistics with FleXScan open source software (v3.1.2) (Takahashi et al., 2008, 2013; Tango and Takahashi, 2005). FleXScan performs a flexibly shaped spatial scan statistic that can detect irregularly shaped clusters. The analysis parameters were set to purely spatial analysis, scanning for clusters with high prevalence rates using models with a binomial distribution and logit link function for this binary diagnostic status outcome and weighted according to the total number of patients tested and traced in a given TCU. The matrix definition file was created based on a spatial weights matrix generated in ArcGIS and the maximum spatial cluster size was set to 10 TCUs. Spatial relationships were set to Delaunay Triangulation with Euclidian distance. TCUs identified as being part of a spatial cluster were visualised with ArcGIS.

\section{Results}

Among 4,378 outpatients tested for the presence of $P$. falciparum malaria infections at BHC between June 2012 and January 2013, $9.1 \%(400 / 4378)$ tested positive. Over half $(55.0 \% ; 2407 / 4378)$ of all patients tested for malaria reported that they were residents of Buguruni and Vingunguti wards, with 13.5\% (325/2407) out of these testing positive. The diagnostic positivity rate was much lower (3.8\%; 75/1971) among the tested patients that came from other wards of Dar es Salaam, including 17 patients who were residents of other regions of Tanzania. Among all tested patients living in Buguruni and Vingunguti wards, 80.6\% (1941/2407) provided a local leader's name, and 46.6\% (1121/2407) were successfully traced back to their residential TCU (Figure 3). Surprisingly, while the home residence TCU leader was unambiguously identified for $73.8 \%$ (240/325) of the patients from the study wards who tested positive for malaria, only $42.3 \%(881 / 2082)$ of those with a negative test result were successfully traced. Accordingly, the diagnostic positivity rate among the tested study ward residents who were successfully traced

Table 1. Malaria test results per ward and neighbourhood, and results of logistic generalised linear models for comparing diagnostic positivity rates of different wards and neighbourhoods.

\begin{tabular}{|c|c|c|c|c|c|c|c|}
\hline Ward & Neighbourhood & Tested patients (n) & Positive cases (n) & Diagnostic positivity & Coefficient & $Z$ value & $\mathbf{P}$ \\
\hline Buguruni & $\begin{array}{l}\text { Kisiwani } \\
\text { Mnyamani } \\
\text { Malapa } \\
\text { Madenge }\end{array}$ & $\begin{array}{c}137 \\
302 \\
48 \\
88\end{array}$ & $\begin{array}{l}31 \\
71 \\
13 \\
17\end{array}$ & $\begin{array}{l}0.23 \\
0.24 \\
0.27 \\
0.19\end{array}$ & $\begin{array}{c}1 \\
1.046436 \\
1.270042 \\
0.830415\end{array}$ & $\begin{array}{c}\text { na } \\
0.185 \\
0.623 \\
-0.548\end{array}$ & $\begin{array}{c}\text { na } \\
0.853 \\
0.533 \\
0.583\end{array}$ \\
\hline Vingunguti & $\begin{array}{l}\text { Mtambani } \\
\text { Mtakuja } \\
\text { Miembeni } \\
\text { Kombo }\end{array}$ & $\begin{array}{c}166 \\
87 \\
54 \\
239\end{array}$ & $\begin{array}{c}33 \\
23 \\
8 \\
44\end{array}$ & $\begin{array}{l}0.20 \\
0.26 \\
0.15 \\
0.18\end{array}$ & $\begin{array}{l}0.848411 \\
1.228827 \\
0.594669 \\
0.771545\end{array}$ & $\begin{array}{c}-0.583 \\
0.649 \\
-1.197 \\
-0.983\end{array}$ & $\begin{array}{l}0.560 \\
0.516 \\
0.231 \\
0.325\end{array}$ \\
\hline Buguruni & All & 575 & 132 & 0.23 & 1 & na & na \\
\hline Vingunguti & All & 546 & 108 & 0.20 & 0.827522 & -1.295 & 0.195 \\
\hline Total & & 1121 & 240 & 0.21 & & & \\
\hline
\end{tabular}

na, not available. 
was considerably higher $(21.4 \% ; 240 / 1121)$ than among untraced patients living in the same wards $(6.6 \% ; 85 / 1286)$. The patients that could not be traced had provided none, unclear or inaccurate information regarding the names of their local leaders, wards, or neighbourhoods (Figure 3). Patients from a total of 411 TCUs were traced, corresponding to $57.3 \%$ of all TCUs in Buguruni and Vingunguti (717). The numbers of traced patients were similar in Buguruni $(n=576)$ and Vingunguti ( $\mathrm{n}=546$ ), and the highest number of patients came from the neighbourhood where the BHC is located (Table 1). No spatial patterns were obvious at the ward or neighbourhood levels, as no significant differences between diagnostic positivity rates were found when the data were aggregated at these coarser scales (Table 1). However, testing for spatial autocorrelation of diagnostic positivity rates in the different residential locations indicated a clustered pattern at the TCU level ( $\mathrm{z}$-score $=2.23, \mathrm{P}=0.026$ ).

Cluster analysis with spatial scan statistics based on the spatial distribution of malaria diagnostic positivity rate identified one small cluster $(\mathrm{P}=0.047)$ of high-infection rates (Figure 2$)$ consisting of only four TCUs within $100 \mathrm{~m}$ of each other, where $100 \%$ of tested patients (seven out of seven) had positive test results.

The total cost for eligible patients to be traced back to their area of residence over a period of eight months was US\$ 10.2 per individual, comprising all personnel and transport costs for conducting this study. The additional workload for laboratory technicians resulting from this study was observed to be readily manageable and did not appreciably affect the routine daily activities of the laboratory staff who filled out $>90 \%$ of the forms correctly.

\section{Discussion}

Despite the known limitations of routine health facility data in terms of representativeness and completeness (Rowe et al., 2009; Tornheim et al., 2010), this exploratory study indicates that routine patient records allow mapping the spatial distribution and heterogeneities of malaria infection rates at high levels of spatial detail (Figure 2) for every second patient tested for malaria at a health facility. This can be achieved at an affordable cost by adding a simple and widely used fine-scale geographic or administrative point of reference to the health facility patient register - in this case we added the name of the patient's local leader that is generally well known in the community. In contrast to previous studies that predicted finescale risk by fitting statistical models to aggregated health facility catchment data (Sturrock et al., 2014) or by actively tracing all patients to their homes (Bejon et al., 2014; Ernst et al., 2006), our approach demonstrates that comparably fine spatial resolutions can be derived from passively collected routine case data. Indeed, cluster analysis with spatial scan statistics identified one cluster of high diagnostic positivity that had a diameter of only $100 \mathrm{~m}$.

This small-scale pilot study, and indeed the overall approach taken, has considerable limitations and caveats that merit careful consideration. The most obvious limitation was that $53.4 \%$ of all tested patients could not be traced back to their residential areas. This might be due to potential selection bias for locations with more readily identifiable TCU leaders, which could possibly lead to an overestimation or underestimation of the actual malaria

\section{Total numbers of patients tested for malaria at $\mathrm{BHC}$} Test results
Patients from Buguruni
or Vingunguti ward

Neighbourhood name provided

Local leader's name provided

Patients successfully traced back to their residential housing cluster 
infection burden. The largest potential opportunity for optimising this approach therefore probably lies in improving rates of successful patient tracing. Note, however, that patient tracing may be more difficult in rural areas with more scattered populations. Indeed, only $27 \%$ of patients were successfully traced by a very similar study conducted in rural Kenya (Stresman et al., 2014). A very successful example with household traceability of up to $100 \%$ is work performed in Solomon Islands and Vanuatu, where a comparable spatial resolution was also achieved based on routinely collected data, including successful integration in an automated GIS platform for identifying areas for targeted response (Kelly et al., 2013). However, the high traceability was only possible by georeferencing all households $(>10,000)$ in the study area beforehand, which might be more a suitable approach in the elimination context of these Pacific Islands compared to fast growing megacities such as Dar es Salaam.

However, perhaps the most important caveat to this pilot study is the clear bias towards successful tracing of malaria-positive cases, compared to malaria-negative cases. This discrepancy is surprising, considering that residential information of the patients was recorded before the patients were tested, but it seems likely that it may have arisen from the understandably greater enthusiasm, priority and effort investment for identifying TCU leaders of patients known to be malaria-infected. The larger number of malaria-negative patients may well have been mistakenly perceived as less interesting to those tasked with mapping the malaria risk, who may not have fully appreciated the statistical necessity to treat malariapositive and malaria-negative patients identically. It will thus be crucial for future studies to minimise the risk of bias in the recording procedure and to blind personnel responsible for patient tracing to the diagnostic outcome of the patients. Furthermore, in order to maximise cost-effectiveness and minimise disease-specific biases, future studies should ideally map several spatially heterogeneous diseases in an integrated manner. It would be essential for further applications of this approach to also record, assess and account for the effect of patient age and the associated immunity level (Bejon et al., 2014; Bisanzio et al., 2015; Yeshiwondim et al., 2009). In the case of Dar es Salaam though, the risk of detectable malaria infection appears to be essentially equivalent across all age groups, following the strongly reduced transmission over the last several years that resulted in loss of exposure-acquired immunity (Msellemu et al., 2016).

Furthermore, the modest scale of this pilot study also represents a clear limitation that needs to be addressed with much more geographically and temporally extensive evaluations. Using only a single public facility clearly limited the coverage and completeness, so much larger scale and evaluation over longer terms will be required to fully assess both the full power and fundamental limitations of this strategy. Using this approach over longer periods of time could also enable more robust assessment of spatial clustering as well as capturing seasonality and other short- and long-term temporal trends.

Future applications of this approach will need to cope with the highly dynamic nature of local government political processes on such fine scales. The identities of local government leaders, especially those of the TCUs, change frequently due to normal electoral, political and demographic processes, so it is essential to regularly and routinely update TCU locations and leadership informa- tion by frequently consulting with local authorities at ward and neighbourhood levels or their equivalents in other settings. In this pilot study, $42.8 \%(820 / 1941)$ of patients that provided a TCU leader's name could not be matched to a location because the name they provided was either wrong or misspelt in such a way that neither automated nor manual matching was possible. A possible solution for this might be to provide health facilities with up-to-date lists of all municipalities, wards, neighbourhoods and TCU leaders, from which patients can choose their respective residential location. Using electronic devices such as tablets or mobile phones for data collection might be very beneficial in this respect, and also in terms of facilitating timely reporting and responses.

The techniques presented here can be extended to include public and private health facilities at any given scale of catchment area, and can be scaled up to other comparable low-income settings with limited resources and no physical address system, wherever a similar local government system exists. In Tanzania, TCUs and their leaders have been established across the mainland and similar fine-scale local government subdivisions, known as sheha, also exist in the Zanzibar archipelago. In malaria-affected regions elsewhere, where the existing administrative structures do not allow for simple replication of this approach, potential alternatives to using the names of local leaders might be self-reported landmarks such as nearby schools, health facilities, churches or mosques (Stresman et al., 2014). Alternatively, a map-book approach, based on printouts of aerial imagery, could be applied but this may well increase cost and burden upon health facilities that are already overstretched, because it requires some time investment in explanation by health facility staff (MacPherson et al., 2013). While the clear shortcoming of both these alternatives is their much coarser spatial resolution, their potential lies in the relatively large patients numbers that can be traced (MacPherson et al., 2013; Stresman et al., 2014).

In addition to the demonstrated functionality of this fine-scale mapping procedure, a clear strength of this approach is that it is affordable and practical because it does not require any active data gathering other than maintaining up-to-date information about the residential location and identities of elected local leaders. Other than that, it relies entirely on routine health facility data which is widely available across many countries with even the most basic health services (Cohen et al., 2013). With regard to malaria control interventions, the approach might have its largest potential when integrated with a GIS-based surveillance system at the local, provincial or national level to generate dynamic risk maps for guiding targeted interventions in real time, thus contributing to effective surveillance-response systems (Tambo et al., 2014; Zhou et al., 2013).

\section{Conclusions}

Recording simple points of reference that community members can readily relate to during routine health facility visits - in this case the names of their local leaders - can be used for mapping spatial heterogeneity in confirmed clinical malaria rates at remarkably fine geographic scales. Such passively collected routine clinical data can be used to identify hotspots of elevated risk, offering a feasible approach to targeting malaria control interventions under 
programmatic conditions. In contrast to traditional active surveillance approaches, such as cross-sectional or incidence cohort surveys, mapping the spatial distribution of malaria infection rates using passively collected routine health facility data offers high spatial resolution at an affordable cost. However, in order to tap the full potential of this approach, optimising the success rate in tracing patients and eliminating biases associated with diagnostic test results will be necessary. Closing these methodological gaps could result in a refined surveillance tool that has the potential to become a scalable, integral, sustainable component of control programmes, which can then target supplementary interventions to foci of elevated risk.

\section{References}

Alemu K, Worku A, Berhane Y, 2013. Malaria infection has spatial, temporal, and spatiotemporal heterogeneity in unstable malaria transmission areas in Northwest Ethiopia. PLoS One 8:e79966.

Bejon P, Williams TN, Liljander A, Noor AM, Wambua J, Ogada E, Olotu A, Osier FHA, Hay SI, Färnert A, 2010. Stable and unstable malaria hotspots in longitudinal cohort studies in Kenya. PLoS Med 7:e1000304.

Bejon P, Williams TN, Nyundo C, Hay SI, Benz D, Gething PW, Otiende M, Peshu J, Bashraheil M, Greenhouse B, Bousema T, Bauni E, Marsh K, Smith DL, Borrmann, S, 2014. A microepidemiological analysis of febrile malaria in Coastal Kenya showing hotspots within hotspots. Elife 3:e02130.

Bhattarai A, Ali AS, Kachur SP, Mårtensson A, Abbas AK, Khatib R, Al-Mafaz A-w, Ramsan M, Rotllant G, Gerstenmaier JF, 2007. Impact of artemisinin-based combination therapy and insecticide-treated nets on malaria burden in Zanzibar. PLoS Med 4:e309.

Bisanzio D, Mutuku F, LaBeaud AD, Mungai PL, Muinde J, Busaidy H, Mukoko D, King CH, Kitron U, 2015. Use of prospective hospital surveillance data to define spatiotemporal heterogeneity of malaria risk in coastal Kenya. Malaria J 14:482.

Bousema T, Drakeley C, Gesase S, Hashim R, Magesa S, Mosha F, Otieno S, Carneiro I, Cox J, Msuya E, Kleinschmidt I, Maxwell C, Greenwood B, Riley E, Sauerwein R, Chandramohan, D, Gosling R, 2010a. Identification of hot spots of malaria transmission for targeted malaria control. J Infect Dis 201:1764-74.

Bousema T, Griffin JT, Sauerwein RW, Smith DL, Churcher TS, Takken W, Ghani A, Drakeley C, Gosling R, 2012. Hitting hotspots: spatial targeting of malaria for control and elimination. PLoS Med 9:e1001165.

Bousema T, Youssef RM, Cook J, Cox J, Alegana VA, Amran J, Noor AM, Snow RW, Drakeley C, 2010b. Serologic markers for detecting malaria in areas of low endemicity, Somalia, 2008. Emerg Infect Dis 16:392-9.

Branch OL, Casapia WM, Gamboa DV, Hernandez JN, Alava FF, Roncal N, Alvarez E, Perez EJ, Gotuzzo E, 2005. Clustered local transmission and asymptomatic Plasmodium falciparum and Plasmodium vivax malaria infections in a recently emerged, hypoendemic Peruvian Amazon community. Malaria J 4:27.

Brooker S, Clarke S, Njagi JK, Polack S, Mugo B, Estambale B, Muchiri E, Magnussen P, Cox J, 2004. Spatial clustering of malaria and associated risk factors during an epidemic in a highland area of western Kenya. Trop Med Int Health 9:75766.

Ceesay SJ, Casals-Pascual C, Erskine J, Anya SE, Duah NO, Fulford AJC, Sesay SSS, Abubakar I, Dunyo S, Sey O, 2008. Changes in malaria indices between 1999 and 2007 in The Gambia: a retrospective analysis. Lancet 372:1545-54.

Chaki PP, Dongus S, Fillinger U, Kelly A, Killeen GF, 2011. Community-owned resource persons for malaria vector control: enabling factors and challenges in an operational programme in Dar es Salaam, United Republic of Tanzania. Hum Resour Health 9:21.

Chaki PP, Mlacha Y, Msellemu D, Muhili A, Malishee AD, Mtema ZJ, Kiware SS, Zhou Y, Lobo NF, Russell TL, Dongus S, Govella NJ, Killeen GF, 2012. An affordable, quality-assured community-based system for high-resolution entomological surveillance of vector mosquitoes that reflects human malaria infection risk patterns. Malaria J 11:172.

Chanda E, Coleman M, Kleinschmidt I, Hemingway J, Hamainza B, Masaninga F, Chanda-Kapata P, Baboo KS, Durrheim DN, 2012. Impact assessment of malaria vector control using routine surveillance data in Zambia: implications for monitoring and evaluation. Malaria J 11:437.

Clark TD, Greenhouse B, Njama-Meya D, Nzarubara B, MaitekiSebuguzi C, Staedke SG, Seto E, Kamya MR, Rosenthal PJ, Dorsey G, 2008. Factors determining the heterogeneity of malaria incidence in children in Kampala, Uganda. J Infect Dis 198:393-400.

Cohen JM, Dlamini S, Novotny JM, Kandula D, Kunene S, Tatem AJ, 2013. Rapid case-based mapping of seasonal malaria transmission risk for strategic elimination planning in Swaziland. Malaria J 12:61.

Cohen JM, Ernst KC, Lindblade KA, Vulule JM, John CC, Wilson ML, 2010. Local topographic wetness indices predict household malaria risk better than land-use and land-cover in the western Kenya highlands. Malaria J 9:328.

D'Acremont V, Lengeler C, Genton B, 2010. Reduction in the proportion of fevers associated with Plasmodium falciparum parasitaemia in Africa: a systematic review. Malaria J 9:240.

DCP, 2004. City profile for Dar es Salaam, Dar es Salaam City Council with advice from cities and health programme. WHO Centre for Development, Kobe, Japan.

de Castro MC, Yamagata Y, Mtasiwa D, Tanner M, Utzinger J, Keiser J, Singer BH, 2004. Integrated urban malaria control: a case study in Dar es Salaam, Tanzania. Am J Trop Med Hyg 71(Supp1.2):103-17.

de Oliveira AM, Mutemba R, Morgan J, Streat E, Roberts J, Menon M, Mabunda S, 2011. Prevalence of malaria among patients attending public health facilities in Maputo City, Mozambique. Am J Trop Med Hyg 85:1002-7.

Dongus S, Mwakalinga V, Kannady K, Tanner M, Killeen GF, 2011. Participatory mapping as a component of operational malaria vector control in Tanzania. In: J. Maantay, S. McLafferty (eds.) Geospatial analysis of environmental health. Geotechnologies and the environment, Volume 4, Part 3, pp. 321-336. Springer, Berlin, Germany.

Dongus S, Nyika D, Kannady K, Mtasiwa D, Mshinda H, Fillinger U, Drescher A, Tanner M, Castro M, Killeen G, 2007. Participatory mapping of target areas to enable operational larval source management to suppress malaria vector mosquitoes in Dar es Salaam, Tanzania. Int J Health Geogr 6:37. 
Dongus S, Nyika D, Kannady K, Mtasiwa D, Mshinda H, Gosoniu L, Drescher AW, Fillinger U, Tanner M, Killeen GF, Castro MC, 2009. Urban agriculture and Anopheles habitats in Dar es Salaam, Tanzania. Geospat Health 3:189-210.

Eriksen J, Tomson G, Mujinja P, Warsame M, Jahn A, Gustafsson L, 2007. Assessing health worker performance in malaria case management of underfives at health facilities in a rural Tanzanian district. Trop Med Int Health 12:52-61.

Ernst KC, Adoka SO, Kowuor DO, Wilson ML, John CC, 2006. Malaria hotspot areas in a highland Kenya site are consistent in epidemic and non-epidemic years and are associated with ecological factors. Malaria J 5:78.

Feachem RGA, Phillips AA, Hwang J, Cotter C, Wielgosz B, Greenwood BM, Sabot O, Rodriguez MH, Abeyasinghe RR, Ghebreyesus TA, 2010. Shrinking the malaria map: progress and prospects. Lancet 376:1566-78.

Gaudart J, Poudiougou B, Dicko A, Ranque S, Toure O, Sagara I, Diallo M, Diawara S, Ouattara A, Diakite, M, Doumbo OK, 2006. Space-time clustering of childhood malaria at the household level: a dynamic cohort in a Mali village. BMC Public Health 6:86.

Geissbühler Y, Chaki P, Emidi B, Govella NJ, Shirima R, Mayagaya V, Mtasiwa D, Mshinda H, Fillinger U, Lindsay SW, 2007. Interdependence of domestic malaria prevention measures and mosquito-human interactions in urban Dar es Salaam, Tanzania. Malaria J 6:126.

Gething PW, Kirui VC, Alegana VA, Okiro EA, Noor AM, Snow RW, 2010a. Estimating the number of paediatric fevers associated with malaria infection presenting to Africa's public health sector in 2007. PLoS Med 7:e1000301.

Gething PW, Smith DL, Patil AP, Tatem AJ, Snow RW, Hay SI, 2010b. Climate change and the global malaria recession. Nature 465:342-5.

Hardy A, Mageni Z, Dongus S, Killeen G, Macklin MG, Majambare S, Ali A, Msellem M, Al-Mafazy AW, Smith M, Thomas C, 2015. Mapping hotspots of malaria transmission from pre-existing hydrology, geology and geomorphology data in the pre-elimination context of Zanzibar, United Republic of Tanzania. Parasite Vectors 8:41.

Jennings JM, Curriero FC, Celentano D, Ellen JM, 2005 Geographic identification of high gonorrhea transmission areas in Baltimore, Maryland. Am J Epidemiol 161:73-80.

Kahama-Maro J, D'Acremont V, Mtasiwa D, Genton B, Lengeler C, 2011. Low quality of routine microscopy for malaria at different levels of the health system in Dar es Salaam. Malaria J 10:1-10.

Kazembe LN, 2007. Spatial modelling and risk factors of malaria incidence in northern Malawi. Acta Trop 102:126-37.

Kazembe LN, Kleinschmidt I, Sharp BL, 2006. Patterns of malaria-related hospital admissions and mortality among Malawian children: an example of spatial modelling of hospital register data. Malaria J 5:93.

Kelly GC, Hale E, Donald W, Batarii W, Bugoro H, Nausien J, Smale J, Palmer K, Bobogare A, Taleo G, Vallely A, Tanner M, Vestergaard LS, Clements AC, 2013. A high-resolution geospatial surveillance-response system for malaria elimination in Solomon Islands and Vanuatu. Malaria J 12:108.

Kitua A, Ogundahunsi O, Lines J, Mgone C, 2011. Conquering malaria: enhancing the impact of effective interventions towards elimination in the diverse and changing epidemiology. J Glob Infect Dis 3:161-5.
Kreuels B, Kobbe R, Adjei S, Kreuzberg C, Von Reden C, Bäter K, Klug S, Busch W, Adjei O, May J, 2008. Spatial variation of malaria incidence in young children from a geographically homogeneous area with high endemicity. J Infect Dis 197:85.

Lengeler C, de Savigny D, Mshinda H, Mayombana C, Tayari S, Hatz C, Degremont A, Tanner M, 1991. Community-based questionnaires and health statistics as tools for the cost-efficient identification of communities at risk of urinary schistosomiasis. Int J Epidemiol 20:796-807.

Lippeveld T, Sauerborn R, Bodart C, 2000. Design and implementation of health information systems. World Health Organization, Geneva, Switzerland.

MacPherson P, Choko AT, Webb EL, Thindwa D, Squire SB, Sambakunsi R, van Oosterhout JJ, Chunda T, Chavula K, Makombe SD, 2013. Development and validation of a global positioning system-based "Map Book" system for categorizing cluster residency status of community members living in high-density urban slums in Blantyre, Malawi. Am J Epidemiol 177:1143-7.

Maharaj R, Morris N, Seocharan I, Kruger P, Moonasar D, Mabuza A, Raswiswi E, Raman J, 2012. The feasibility of malaria elimination in South Africa. Malaria J 11:423.

Maheu-Giroux M, Castro MC, 2013. Impact of community-based larviciding on the prevalence of malaria infection in Dar es Salaam, Tanzania. PLoS One 8:e71638.

malERA Consultative Group on Monitoring, 2011. A research agenda for malaria eradication: monitoring, evaluation, and surveillance. PLoS Med 8:e1000400.

Mamdani M, Bangser M, 2004. Poor people's experiences of health services in Tanzania: a literature review. Reprod Health Matter 12:138-53.

Mayala B, Mboera L, Gwacha F, 2004. Mapping of cholera risks using Geographical Information System in Ilala District, Tanzania. Tanzania J Health Res 5:8-12.

Mirghani SE, Nour BY, Bushra SM, Elhassan IM, Snow, RW, Noor AM, 2010. The spatial-temporal clustering of Plasmodium falciparum infection over eleven years in Gezira State, The Sudan. Malaria J 9:172.

Moonen B, Cohen JM, Snow RW, Slutsker L, Drakeley C, Smith DL, Abeyasinghe RR, Rodriguez MH, Maharaj R, Tanner M, Targett G, 2010a. Operational strategies to achieve and maintain malaria elimination. Lancet 376:1592-603.

Moonen B, Cohen JM, Tatem AJ, Cohen J, Hay SI, Sabot O, Smith DL, 2010b. A framework for assessing the feasibility of malaria elimination. Malaria J 9:322.

Moran PA, 1948. The interpretation of statistical maps. J Roy Stat Soc B 10:243-51.

Msellemu D, Namango HI, Mwakalinga, VM, Ntamatungiro AJ, Mlacha Y, Mtema ZJ, Kiware S, Lobo NF, Majambere S, Dongus S, Drakeley CJ, Govella NJ, Chaki PP, Killeen GF, 2016. The epidemiology of residual Plasmodium falciparum malaria transmission and infection burden in an African city with high coverage of multiple vector control measures. Malaria J 15:288.

Mtasiwa D, Siegfried G, Tanner M, Pichette P, 2003. The Dar es Salaam City/Region minimum package of health and related management activities: from managing diseases to managing health systems. Dar es Salaam City Medical Office of Health, Dar es Salaam, Tanzania.

Mtove G, Amos B, Nadjm B, Hendriksen I, Dondorp AM, Mwambuli A, Kim DR, Ochiai RL, Clemens JD, von Seidlein 
L, 2011. Decreasing incidence of severe malaria and community-acquired bacteraemia among hospitalized children in Muheza, north-eastern Tanzania, 2006-2010. Malaria J 10:320.

Mueller I, Slutsker L, Tanner M, 2011. Estimating the burden of malaria: the need for improved surveillance. PLoS Med 8:e1001144.

Murray CJL, Rosenfeld LC, Lim SS, Andrews KG, Foreman KJ, Haring D, Fullman N, Naghavi M, Lozano R, Lopez AD, 2012. Global malaria mortality between 1980 and 2010: a systematic analysis. Lancet 379:413-31.

Namango I, 2012. Malaria parasite infection risk in urban Dar es Salaam, Tanzania: the role of routine outdoor nocturnal activities and common livelihoods among adults. University of Nairobi, Nairobi, Kenya.

Nourein AB, Abass MA, Nugud AHD, El Hassan I, Snow RW, Noor AM, 2011. Identifying residual foci of Plasmodium falciparum infections for malaria elimination: the urban context of Khartoum, Sudan. PLoS One 6:e16948.

Nsimba SE, Massele AY, Eriksen J, Gustafsson LL, Tomson G, Warsame M, 2002. Case management of malaria in under-fives at primary health care facilities in a Tanzanian district. Trop Med Int Health 7:201-209.

O’Meara WP, Mangeni JN, Steketee R, Greenwood B, 2010. Changes in the burden of malaria in sub-Saharan Africa. Lancet Infect Dis 10:545-55.

Oduro AR, Bojang KA, Conway DJ, Corrah T, Greenwood BM, Schellenberg D, 2011. Health centre surveys as a potential tool for monitoring malaria epidemiology by area and over time. PLoS One 6:e26305.

Pinchoff J, Henostroza G, Carter BS, Roberts ST, Hatwiinda S, Hamainza B, Hawela M, Curriero FC, 2015. Spatial patterns of incident malaria cases and their household contacts in a single clinic catchment area of Chongwe District, Zambia. Malaria J 14:305.

Roll Back Malaria, 2006. Guidelines for core population coverage indicators for roll back malaria: to be obtained from household surveys. Maryland: Roll Back Malaria, Vernier, Switzerland.

Rowe AK, Kachur SP, Yoon SS, Lynch M, Slutsker L, Steketee RW, 2009. Caution is required when using health facilitybased data to evaluate the health impact of malaria control efforts in Africa. Malaria J 8:209.

Steketee RW, Campbell CC, 2010. Impact of national malaria control scale-up programmes in Africa: magnitude and attribution of effects. Malaria J 9:299.

Stresman GH, Stevenson JC, Owaga C, Marube E, Anyango C, Drakeley C, Bousema T, Cox J, 2014. Validation of three geolocation strategies for health-facility attendees for research and public health surveillance in a rural setting in western Kenya. Epidemiol Infect 142:1978-89.

Sturrock HJ, Cohen JM, Keil P, Tatem AJ, Le Menach A, Ntshalintshali NE, Hsiang MS, Gosling RD, 2014. Fine-scale malaria risk mapping from routine aggregated case data. Malaria J 13:421.

Takahashi K, Kulldorff M, Tango T, Yih K, 2008. A flexibly shaped space-time scan statistic for disease outbreak detection and monitoring. Int J Health Geogr 7:14.

Takahashi K, Yokoyama T, Tango T, 2013. FleXScan v3.1.2: software for the flexible scan statistic. National Institute of Public Health, Tokyo, Japan.

Tambo E, Ai L, Zhou X, Chen JH, Hu W, Bergquist R, Guo JG, Utzinger J, Tanner M, Zhou XN, 2014. Surveillance-response systems: the key to elimination of tropical diseases. Infect Dis Poverty 3:17.

Tango T, Takahashi K, 2005. A flexibly shaped spatial scan statistic for detecting clusters. Int J Health Geogr 4:11.

Teuscher T, 1992. Household-based malaria control in a highly endemic area of Africa (Tanzania): determinants of transmission and disease and indicators for monitoring-Kilombero Malaria Project. Mem Inst Oswaldo Cruz 87:121-30.

Tornheim JA, Manya AS, Oyando N, Kabaka S, O'Reilly CE, Breiman RF, Feikin DR, 2010. The epidemiology of hospitalization with diarrhea in rural Kenya: the utility of existing health facility data in developing countries. Int J Infect Dis 14:499-505.

United Republic of Tanzania, 2006. National guidelines for diagnosis and treatment of malaria. United Republic of Tanzania ed., Dar es Salaam, Tanzania.

United Republic of Tanzania, 2013. 2012 Population and housing census; population distribution by administrative areas. National Bureau of Statistics, Tanzania, Dar es Salaam, Tanzania.

WHO, 2007. Malaria elimination: a field manual for low and moderate endemic countries. World Health Organization, Geneva, Switzerland.

WHO, 2012. Disease surveillance for malaria elimination: an operational manual. World Health Organization, Geneva, Switzerland.

WHO, 2013. World malaria report 2013. World Health Organization, Geneva, Switzerland.

Wimberly MC, Midekisa A, Semuniguse P, Teka H, Henebry GM, Chuang TW, Senay GB, 2012. Spatial synchrony of malaria outbreaks in a highland region of Ethiopia. Trop Med Int Health 17:1192-201.

Woolhouse MEJ, Dye C, Etard JF, Smith T, Charlwood JD, Garnett GP, Hagan P, Hii JLK, Ndhlovu PD, Quinnell RJ, Watts CH, Chaniawana SK, Anderson RM, 1997. Heterogeneities in the transmission of infectious agents: implications for the design of control programs. P Natl Acad Sci USA 94:338-42.

Yeshiwondim AK, Gopal S, Hailemariam AT, Dengela DO, Patel HP, 2009. Spatial analysis of malaria incidence at the village level in areas with unstable transmission in Ethiopia. Int $\mathrm{J}$ Health Geogr 8:5.

Zacarias OP, Andersson M, 2011. Spatial and temporal patterns of malaria incidence in Mozambique. Malaria J 10:189.

Zanzibar Malaria Control Programme, 2010. Zanzibar malaria early epidemic detection system biannual report, year-end 2009. Zanzibar Malaria Control Programme, Zanzibar.

Zhou XN, Bergquist R, Tanner M, 2013. Elimination of tropical disease through surveillance and response. Infect Dis Poverty 2:1. 